\title{
Perceptions of Young Adults towards Live - In Relationship
}

\author{
Mandava Hemalatha ${ }^{1 *}$ and Nasreen Banu ${ }^{2}$ \\ ${ }^{1}$ Department of Human Development and Family Studies, College of Home Science, Professor \\ Jayashankar Telangana State Agricultural University, Hyderabad, Telangana, India \\ ${ }^{2}$ AICRP, PJTSAU, Hyderabad-500 004, Telangana, India \\ *Corresponding author
}

A B S T R A C T

\section{Key w ords \\ Live-in relationship, Young adults, Perceptions and cohabitation \\ Article Info \\ Accepted: \\ 16 August 2018 \\ Available Online: \\ 10 September 2018}

\begin{abstract}
A new trend is fast emerging in the society all over the world where two adults of opposite sex giving a complete go by to the institution of marriage decide to live-in relationship which almost resembles a marriage. The present study was undertaken to study the Perceptions of Young adults (80 students both males and females) towards Live-in relationship by purposive random sampling method. Self-developed questionnaire was used to measure the perceptions of young adults towards live-in relationship. Twin cities of Hyderabad and Secunderabad were selected for the study. This scale totally consists of 35 questions which were sub divided into 5 categories like positive perceptions, Negative perceptions, Socio-cultural factors, Economic and educational factors, and consequences of living relationship. Results indicated that no significant difference was found between male and female regarding perceptions towards live-in relationship.
\end{abstract}

\section{Introduction}

Young adulthood is the stage of establishing personal and financial independence and establishing and consolidating a career. For many, it is also the time in which individuals select a partner, develop an ongoing intimate relationship and begin a family. Development of logical, analytical, and abstract thinking occurs. A personal code of ethics develops.

A live-in relationship in which an unmarried couple live together under the same roof in a long term relationship that resembles a marriage is known as a live- in relationship. Thus, it is the type of arrangement in which a man and woman live together without getting married. This form of relationship has become an alternate to marriage in metropolitan cities in which individual freedom is the top priority amongst the youth and nobody wants to get entangled into the typical responsibilities of a married life. Agreement between the partners is the essence of such relationship. Young generation across the world are increasingly opting for such relationship called a live-in relationship which is primarily meant for satisfying the biological need of each other and also to get a long term companionship.

Live-in relationship is a de facto union in which couple shares common bed-room without solemnizing marriage. It is non- 
marital relationship prevailing in West with the different name like, common law marriages, informal marriages or marriage by habit, deemed marriages etc. It is a form of interpersonal status which is legally recognized in some jurisdictions as a marriage even though no legally recognized marriage ceremony is performed or civil marriage contract is entered into or the marriage registered in a civil registry.

Human relationships are complex and marriage is a huge responsibility. Today, young generation enters into various types of relationships in order to satisfy their physical, mental, emotional and financial needs. It has become a growing trend in youngsters in metro cities. The last few decades has however seen the advent of a new form of "living relationship", where men and women cohabit together without entering into marriage. The traditional Indian society however disapproved of such 'living -in relationship' arrangements, for several reasons. Society revered the institution of marriage. An Indian woman was expected to remain a virgin till she married, but live-in relationship contradicted this tradition. Different people will have different perceptions about living relationship. However there are some positive and negative consequences in Living relationship.

The purpose of this study is to find out the gender differences in perceptions of young adults in twin cities of Hyderabad and Secunderabad and also to know what levels are they exposed to living relationship. To further examine how various factors influence to go for Living relationship. Hence present study was proposed

\section{Background}

"Live-in relationship" might be a new term but the concept is ancient. In the Vedas, we find
Gandharva marriage type, in which a man and a woman mutually consent to get married. This neither involves the family of the couple nor a particular ritual to solemnise the marriage. It is just a word-of-mouth commitment. But it still comes under the purview of marriage. Although a couple was united by means of a Gandharva vivaaha, the commitment and responsibility was identical to any of the other types of marriages ordained in the traditional texts. (Perhaps it is worthwhile to mention here that the concept of child marriage is nonexistent in the Vedas; boys and girls were married only after they attained puberty).

According to Weigel, "date," in the context of relationships, reaches back to 1896 . It was first used in a newspaper column in which a young man laments that his girlfriend is seeing other people-that they are "fillin' all my dates," as in "the dates on her calendar."

The custom of men and women living together without marriage has been in practice for millenniums. Since ancient times, the Nawabs, princes and wealthy men in India not only had several wives, but also several live-in women in their Zenanas. It was not at all considered 'immoral' for men to have live-in relationships with women outside their marriage.

The origin of live-in relationship can be traced out with the western countries where it is a proven fact that more than two-thirds of the married couples lived together before getting married. Live-in relationship has now been used as an alternative of marriage but it is not seriously so. It has been termed as a cohabitation of two people not necessarily of the opposite sex but they may also be of the same sex. Now-a-days, people particularly younger generation is becoming more materialistic than before and there has been manifold degradation of moral values and 
emotional bonding amongst partners. No single partner is prepared to take up the responsibility of the other partner and be committed to him or her for a lifetime.

The live-in-relationships are earlier in existence in the form of 'maitrayakarars' which has been practiced in some parts of Gujarat. There is a gradual transition from the sacrament of arranged marriages to love marriages and ultimately to live-in relationships, due to many reasons like lack of tolerance and commitment

Cassandra M. Fleck (2014) found that students identify many factors of a healthy relationship that have been conceptualized within the Healthy Relationships/Equality wheel. However, their understanding of abusive relationships was limited to physical abuse. Adolescent dating relationships were a significant milestone in human development. However, it was evident based on this study that they are complex and ambiguous.

Mohitchhibber, Aditya Singh (2015) stated that the concept of analyzing the level of compatibility before a couple formally tie the knot and gets into a socially more acceptable bond is practical in today's times when the rate of divorces and broken marriages is at an all-time high.

Cassandra (2014) conducted a study on Adolescent Perceptions of "Healthy" Dating Relationships: Implications for Programming and results Participants identified several aspects of healthy and unhealthy relationships throughout the interviews. Often the subjects appeared to have difficulty in describing the definitions of healthy and unhealthy, suggesting that there is ambiguity and differing opinions within the topic. It is evident from this study that students identify many factors of a healthy relationship that have been conceptualized within the Healthy
Relationships/Equality wheel. However, their understanding of abusive relationships is limited to physical abuse. Adolescent dating relationships are a significant milestone in human development. However, it is evident based on this study that they are complex and ambiguous

\section{Materials and Methods}

Self-developed questionnaire was prepared. The total scale was sub divided into 5 categories which consists of positive perceptions, Negative perceptions, Sociocultural factors, Economic and educational factors, and consequences of living relationship...Perceptions of Young adults towards Live-in relationship checklist consisted of 35 statements, which were arranged on 5 point scale i.e., Strongly Agree (SA) is marked as 5; Agree(A) marked as 4 Un Decided(UD) marked as 3; Disagree (D) marked as 2 and Strongly Disagree (SD) marked as 1. The total scores were further grouped as High (very much interested in livein relationship); moderate (interested in live-in relationship) and low (not interested in live-in relationship).

As Survey method goes deep into the psyche of the audience and analyses the target audiences. The survey questionnaire was distributed in colleges to collect information from the target audience on the above mentioned areas. The present study is aimed to study the "Perceptions of Young adults towards Live-in relationship". Based on the nature of the problem and objectives, Ex-post facto research design was adopted for conducting the study. Co-educational colleges from Hyderabad city were selected for this study. Young adults between the age group of 21 to 30 years were selected.

In the present study independent and dependent variables were taken to find out the 
relationship between them. The demographic variables chosen for the study comprise of young adults related factors, which include age, gender, and education. The dependent variables chosen for the study are personal experiences and perceptions of young adults on living relationship, knowledge and information about living relationship. The data obtained was tabulated and analyzed by using percentages and frequencies. To find out the gender differences between male and female ' $t$ ' test was used.

\section{Results and Discussion}

Equal number of respondents of both the gender i.e., out of 80 college students 40 $(50 \%)$ were boys \& $40(50 \%)$ were girls.

From table 1, it is clear that and equal sample of young adults from both the genders were taken as sample for the study on Living relationship. Sample of the present study age ranged between 21 to 27 years.

From figure 1 it was clear that one-fourth $(25 \%)$ of the of the male sample were having 23 years, $(23 \%)$ were having 24 years, $(20 \%)$ were having 22 years and equal percentage i.e., (13\%) were having 21 and 25 years, (4\%) were having 26 years and very few (2\%) were in the age of 27 years.

From figure 2 it was clear that one-fourth of the female sample were having 23 years, (23\%) were having 22 years, $(20 \%)$ were having 24 years, $(15 \%)$ were having 21 years, $(13 \%)$ were having 25 years and remaining very few (4\%) were in the age of 26 years.

As $t$ (stat) value is less than $t$ (critical) value, there was no significant difference between male and female perceptions towards live-in relationship (Table 2). In the present generation women were becoming more expressive and enjoying the gender equity. No live-in relationship will occur without the participation of female. Here the study reveals that females were also having same positive perceptions towards live-in relationship as males have, as dating sites too play an important role in young adults to commit for live-in relationship. Online dating is no longer seen as a last attempt for the desperate and lonely to find their soul mate.

Table.1 General profile and distribution of the sample $\mathrm{N}=80$

\begin{tabular}{|c|c|c|c|c|c|c|c|c|}
\hline \multirow[t]{2}{*}{ S. No } & \multicolumn{2}{|c|}{ Profile } & \multicolumn{2}{|c|}{ Boys $(\mathrm{N}=40)$} & \multicolumn{2}{|c|}{ Girls $(\mathrm{N}=40)$} & \multicolumn{2}{|l|}{ Total } \\
\hline & & & Frequency & Percentage & Frequency & Percentage & Frequency & Percentage \\
\hline & \multicolumn{8}{|c|}{ Age of the Adolescents } \\
\hline 1 & (a) & 21 years & 5 & $13 \%$ & 6 & $15 \%$ & 11 & $14 \%$ \\
\hline 2 & (b) & 22 years & 8 & $20 \%$ & 9 & $23 \%$ & 17 & $21 \%$ \\
\hline 3 & (c) & 23 years & 10 & $25 \%$ & 10 & $25 \%$ & 20 & $25 \%$ \\
\hline 4 & (d) & 24 years & 9 & $23 \%$ & 8 & $20 \%$ & 17 & $21 \%$ \\
\hline 5 & (e) & 25 years & 5 & $13 \%$ & 5 & $13 \%$ & 10 & $12 \%$ \\
\hline 6 & (f) & 26 years & 2 & $4 \%$ & 2 & $4 \%$ & 4 & $5 \%$ \\
\hline 7 & (g) & 27 years & 1 & $2 \%$ & 0 & $0 \%$ & 1 & $2 \%$ \\
\hline & (h) & Total & 40 & $100 \%$ & 40 & $100 \%$ & 80 & $100 \%$ \\
\hline
\end{tabular}


Table. 2 T-test results

\begin{tabular}{|c|c|c|c|c|c|}
\hline & Mean & Variance & SD & t-stat & t-critical \\
\hline Male & 114.58 & 114.76 & 10.71 & 0.76 & 1.99 \\
\hline Female & 112.95 & 68.31 & 8.26 & & \\
\hline
\end{tabular}

Fig.1 Distribution of male sample based on their age

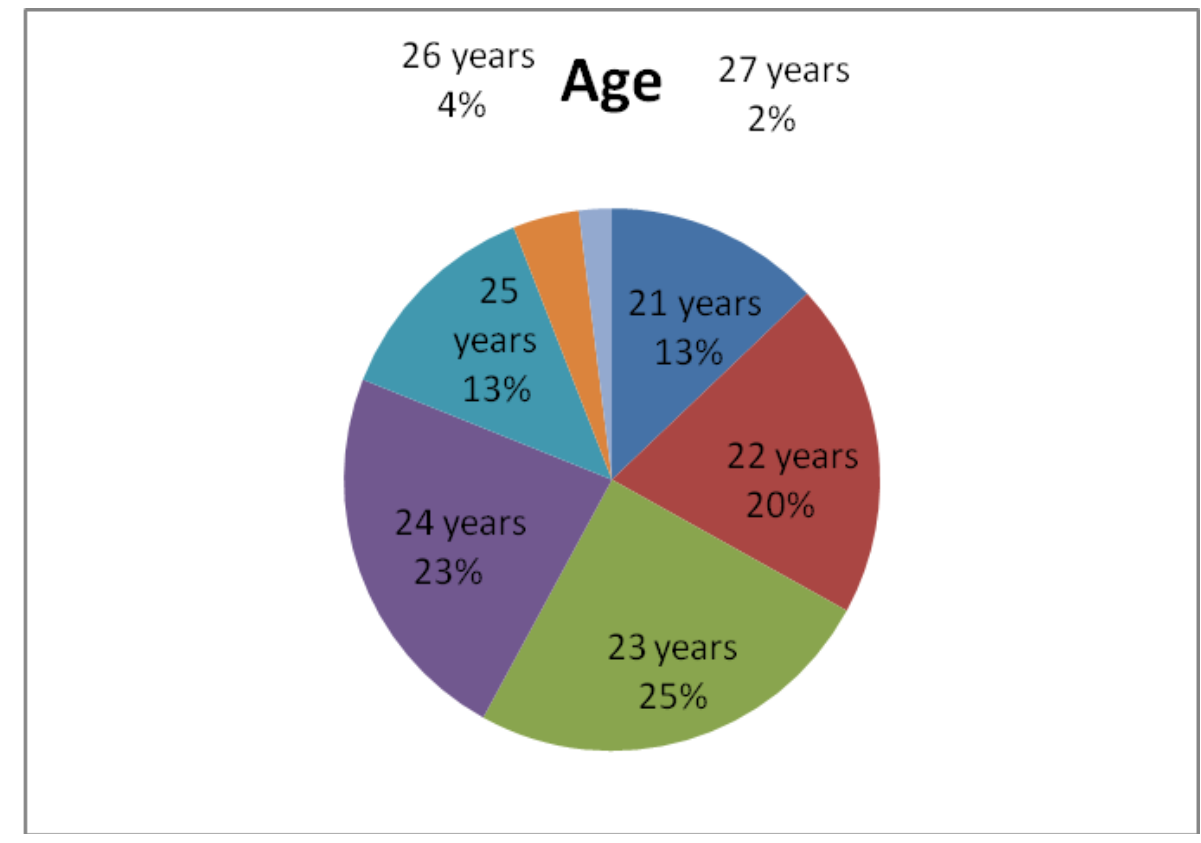

Fig.2 Distribution of female sample based on their age

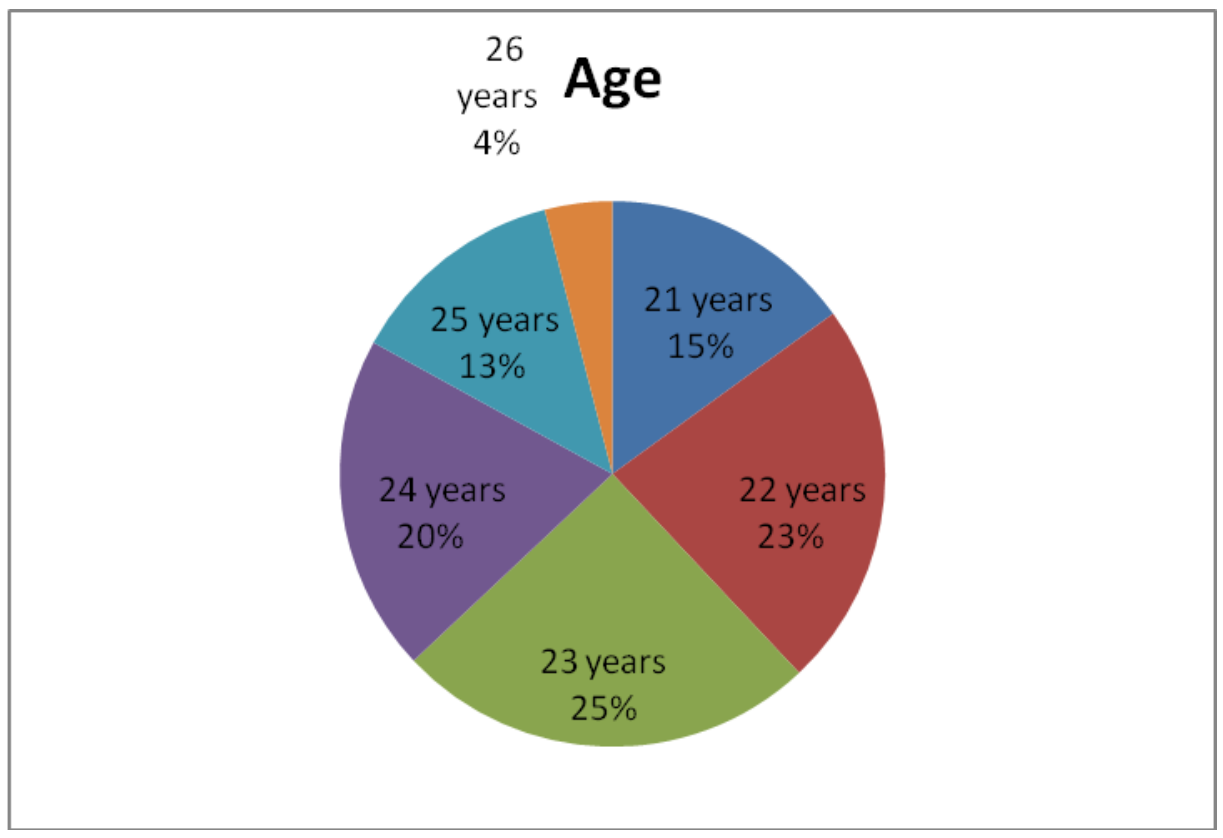


Tinder, a dating app which the New York Times estimated to have upwards of 50 million active users, stated that while men spend 7.2 minutes in an average session, women spend 8.5 minutes swiping through options. This study shows that women spend much time on searching a partner for live in relationship than men which infers that females were having positive perceptions towards live-in relationship as males.

Live-in relationships are extremely popular among educated urban classes as a way of keeping away from the restrictions and inequalities of institutionalized marriages. After going through many reviews and laws available in India, live-in relationship can never replace the institution of marriage. Such a relationship can in no way offer the kind of security and emotional fulfilment that a marriage does. Some people feel that there is no harm in a live-in relationship if it is a prelude to marriage, as it helps one to know the better half better.

The present study explored the perceptions of young adults of both the gender. Findings indicated that an overlap existed between both perceptions such as positive and negative. The major key findings of the present study revealed that there were no gender differences among male and females regarding perceptions on live-in relationship and it was also found that young adults were giving more priority to the Indian culture and societal norms. Data results also demonstrated that in present situation though many were having positive perceptions but they were not willing to for live-in relationship because of the cultural values.

Further research is needed in order to determine the underlying factors behind these results. However it does provide new insight into the nature and perceptions of young adults about living relationship

\section{References}

Fleck, M.C., 2014. Adolescent Perceptions of "Healthy" Dating Relationships: Implications for Programming, Counselor Education Master's Theses. 173.

Chhibber, M., and Singh. A. 2015. Live-in relationships: An ethical and a moral dilemma? International Journal of Applied Research. 1(8): 74-77.

Sahu, M.K. 2014. Live-in relationship: national \& international perspective Nhlu jlss vol. IV, 2231-5594

Laura S., (2015, February 17) Available at http://time.com/3711902/men-usedating-apps-more-tinder/

Nick bilton. (2014, October 29) Tinder, the Fast-Growing Dating App, Taps an Age-Old Truth, New York times. Available at https://www.nytimes. com/2014/10/30/fashion/tinder-the-fastgrowing-dating-app-taps-an-age-oldtruth.html.

Fleck, C.M. 2014. Adolescent Perceptions of Healthy Dating Relationships: Implications for Programming" Counselor Education Master's Theses. 173

\section{How to cite this article:}

Mandava Hemalatha and Nasreen Banu. 2018. Perceptions of Young Adults towards Live - In Relationship. Int.J.Curr.Microbiol.App.Sci. 7(09): 2221-2226. doi: https://doi.org/10.20546/ijcmas.2018.709.274 